\title{
PLURALIDADE DA PRODUÇÃO CIENTÍFICA ACADÊMICA NO CAMPO DAS HUMANIDADES: O caso das licenciaturas em pedagogia e história
}

\author{
PLURALIDAD DE LA PRODUCCIÓN CIENTÍFICA ACADÉMICA EN EL CAMPO \\ DE LAS HUMANIDADES: el caso de las licenciaturas en pedagogía e historia
} PLURALITY OF ACADEMIC SCIENTIFIC PRODUCTION IN THE FIEL OF
HUMANITIES: the case of the degrees in pedagogy and history Daniel Luciano Gevehr
Professor Doutor do Programa de Pós-Graduação
em Desenvolvimento Regional (PPGDR)
Faculdades Integradas de Taquara (FACCAT)
Taquara - RS, Brasil.
danielgevehr@hotmail.com
Shirlei Alexandra Fetter
Mestranda pelo Programa de Pós-Graduação em
Desenvolvimento Regional (PPGDR) da FACCAT.
Taquara - RS, Brasil.
shirleiaf@aluno.faccat.br

Resumo: Este artigo tem por essência, explorar os temas de pesquisa selecionados para o desenvolvimento dos Trabalhos de Conclusão de Curso (TCC) das licenciaturas em Pedagogia e História, compreendidas no campo das Humanidades. Apresentou-se como recorte espacial as Faculdades Integradas de Taquara (FACCAT), uma instituição comunitária localizada no Vale do Paranhana/RS. Os dados coletados sobre os Trabalhos de Conclusão de Curso desenvolvidos pelos acadêmicos compreendem o período de 2007 até 2016, procurando identificar os temas recorrentes nas pesquisas de conclusão de curso relacionando-os a excessiva valorização da produção em grande quantidade. Buscou-se, à luz da teoria de diversos autores que estudam a questão, dialogar sobre a proposta de estudo. Durante a análise pode-se perceber que os estudantes do curso de Pedagogia sentem maior necessidade de desenvolver pesquisas que privilegiam os conceitos relacionados com a escolarização. Já os concluintes do curso de História exploram muito mais temas como a memória, a religiosidade e as questões de gênero, atentando para o debate interdisciplinar. Contudo, percebe-se, a tendência em aproximar os saberes produzidos no meio acadêmico com as necessidades inerentes à sua prática cotidiana. Assim problematizando, os licenciandos demonstram preocupação no tratamento com questões contemporâneas bastante próximas a realidade.

Palavras-chave: Produção. Interesse de pesquisa. Trabalho de Conclusão de Curso. Diversidade. Licenciaturas.

\begin{abstract}
This article has as essence to explore the selected research topics for the development of the works of conclusion of course (TCC) of degrees in Pedagogy and History, included in the field of Humanities. The Integrated College of Taquara (FACCAT), a community institution located in the Paranhama Valley/RS, present as spatial recorte. The data collected on the Course Completion Works developed by the academics comprise the period from 2007 to 2016, trying to identify the recurrent themes in the course completion research relating them to the excessive valorization of production in large quantity. It was sought, in the light of the theory of several authors who study the question, to discuss the study proposal. During the analyses it can be noticed that the students of the Pedagogy course feel a greater need to develop research that privileges the concepts related to schooling. The graduates of the History course explore many more topics such as memory, religiosity and gender issues, attention to the interdisciplinary debate. However, one can perceive the tendency to approximate the knowledge produced in the academic environment with the needs inherent to their daily practice. Thus problematizing, the licensees demonstrate concern in the treatment with contemporary questions quite close to the reality.
\end{abstract}

Keyword: Production. Research. Completion of course work Diversity. Bachelor degress.

Resumen: Este artículo tiene por esencia, explorar los temas de investigación seleccionados para el desarrollo de los Trabajos de Conclusión de Curso (TCC) de las licenciaturas en Pedagogía e Historia, comprendidas en el campo de las Humanidades. Se presentó como recorte espacial las Facultades Integradas de Taquara (FACCAT), una 
institución comunitaria ubicada en el Valle del Paranhana / RS. Los datos recogidos sobre los Trabajos de Conclusión de Curso desarrollados por los académicos comprenden el período de 2007 hasta 2016, buscando identificar los temas recurrentes en las encuestas de conclusión de curso relacionándolos con la excesiva valorización de la producción en gran cantidad. Se buscó, a la luz de la teoría de diversos autores que estudian la cuestión, dialogar con la propuesta de estudio. Durante el análisis se puede percibir que los estudiantes del curso de Pedagogía sienten mayor necesidad de desarrollar investigaciones que privilegian los conceptos relacionados con la escolarización. Los concluyentes del curso de Historia explotan mucho más temas como la memoria, la religiosidad y las cuestiones de género, atentando para el debate interdisciplinario. Sin embargo, se percibe, la tendencia a aproximar los saberes producidos en el medio académico con las necesidades inherentes a su práctica cotidiana. Así problematizando, los licenciandos demuestran preocupación en el tratamiento con cuestiones contemporáneas bastantes próximas a la realidad.

Palabras clave: Producción. Interés de investigación. Proyecto final de curso. Diversidad. Licenciaturas.

\section{INTRODUÇÃO}

A aproximação entre o espaço de produção acadêmico e a sociedade é, talvez, um dos maiores desafios a ser conquistado na contemporaneidade. Na medida em que a criação de novas instituições de ensino superiores [públicas e privadas] e de novos cursos de graduação e PósGraduação chega, paulatinamente, as regiões mais distantes dos grandes centros urbanos do Brasil [que tradicionalmente são considerados os grandes centros de produção acadêmica] é preciso também repensar a dinâmica, através da qual a universidade estabelece o diálogo com a sociedade, em especial na região na qual está inserida.

A partir dessa dimensão, que procura refletir sobre a relação entre a produção científica no meio acadêmico e sua relação com o meio social - e de forma mais pontual sobre a produção acadêmica de egressos dos cursos de graduação - discutimos o processo que envolve a atuação de professores e pesquisadores acadêmicos, que buscam dar sentido e continuidade a sua atuação profissional.

Acreditamos, nessa acepção, que a formação docente pode ser compreendida como propõe Nóvoa (1991), para quem esse processo busca ampliar o conhecimento, proporcionando novas perspectivas, novos olhares, condicionando-se a constantes mudanças que visem alcançar níveis qualitativos. De certo modo, o tema proposto nesse estudo, aborda as questões que discutem a relevância sobre as indagações a respeito do cenário educacional no cotidiano prático da Universidade.

O estudo procura realizar uma reflexão crítica [através dos princípios fundamentais que discutem a produção científica, mensurando quantitativamente] e sua relação com a formação integral do graduando acerca da produção de conhecimento desenvolvido, através das pesquisas de Trabalho de Conclusão de Curso, por alunos na Universidade e a sua relação com o contexto social dos acadêmicos. Parte-se da premissa de que a Universidade - enquanto instância mediadora da Educação - deva ser entendida como instituição coletiva, cultural e patrimonial, obviamente, em termos legais, sob a perspectiva democrática. Precisa-se inserir a reflexão no contexto educativo continuamente, através de atividades, métodos, procedimentos, recursos e técnicas que possibilitam aos alunos, novas e significativas aprendizagens, transcorrendo de maneira produtiva (FAZENDA, 1991).

A pesquisa tem dimensão essencialmente qualitativa, objetivando a exploração dos temas de pesquisa selecionados para o desenvolvimento dos Trabalhos de Conclusão de Curso (TCC) das licenciaturas em Pedagogia e História. Busca-se refletir criticamente sobre a produção acadêmica desenvolvida durante uma década de pesquisas, isto é, do ano de 2007 a 2016, resultante da escrita de monografias de autoria dos concluintes dos cursos de licenciaturas em História e Pedagogia. Efetivou-se a coleta de dados por meio de um levantamento dos trabalhos publicados e disponibilizados, no interior da biblioteca Eldo Ivo Klain, pertencente às Faculdades Integradas de Taquara - FACCAT.

O recorte da pesquisa é, portanto, as Faculdades Integradas de Taquara (FACCAT), uma instituição de ensino comunitária, localizada no município de Taquara, Vale do Paranhana, Rio Grande do Sul. A instituição, criada em 1969, tem caráter comunitário e atualmente oferece 20 cursos de graduação, além de cursos de especialização e mestrado. De acordo com a última avaliação do Ministério da Educação (2016), a FACCAT ocupa o $4^{\circ}$ lugar no ranking das melhores 
Faculdades Integradas do Brasil. A IES apresenta, como missão, promover a articulação com a comunidade regional, através do eixo ensino, pesquisa e extensão, se colocando como um espaço de aproximação entre a produção científica, a criação e a inovação e a comunidade regional do Vale do Paranhana.

No caso específico da pesquisa, buscamos explorar com intensidade os temas de pesquisa selecionados para o desenvolvimento dos Trabalhos de Conclusão de Curso (TCC) das licenciaturas em Pedagogia e História, compreendidas no campo das Humanidades. Dessa forma, a pesquisa se vale de um recorte, que toma como referência os Cursos já citados, uma vez que os dois cursos tem como finalidade a formação de professores para a atuação na educação básica da região.

Com isso, aprofundamos a discussão sobre as relações que se estabelecem entre a produção dos Trabalhos de Conclusão de Curso e a aplicabilidade dos resultados dessas manufacturas. A análise de Macedo e Souza (2010), sobre o produtivismo acadêmico, expressa a materialização em artigos, definindo-os como "mercadorias" que contribuem para o "mal-estar" da academia brasileira. Por enquanto, a produção intelectual é um acúmulo reatualizando-se anualmente.

Selecionado como recorte da pesquisa, os Cursos de Licenciatura em Pedagogia e História da FACCAT, considera-se que ambos estão constituídos a partir da missão [institucional] de formar professores para atuação nas comunidades. Além disso, a incompatibilidade com a quantidade de publicações é utilizada como o principal critério para avaliar a produtividade de um pesquisador. Por outro lado, principalmente no campo das ciências humanas, se insere a produtividade na vida profissional dos pesquisadores, fomentando o desenvolvimento científico e a produção em larga escala (BIANCHETTI; VALLE; PEREIRA, 2015).

Tendo essas questões como ponto de partida, acredita-se que esse tipo de avaliação, buscou-se a reflexão e o questionamento sobre a produção de sentidos, pautados no controle e na contabilidade, podendo dar-se o nome de produtivismo, uma vez que, buscou-se o resultado de uma longa trajetória epistemológica, aplicados as dimensões pedagógica e social, em que a percepção sobre o objeto decorre de uma práxis histórica e social desenvolvidos pelos acadêmicos concluintes.

Outro ponto que se evidencia é a discussão sobre o impacto do produtivismo na universidade [enquanto espaço de produção e difusão do saber] teve como princípios a transmissão e a propagação do conhecimento em âmbito cultural, científico e tecnológico, articulando pesquisa, docência e estudo integrando-se a vida social em constante diálogo. Nesse sentido, Chauí (2001) acrescenta que o conhecimento é guiado por necessidades inseparáveis da essência de um ser, tanto do ponto de vista de sua invenção ou descoberta, como de sua transmissão do conhecimento.

No caso específico do estudo, percebe-se neste panorama, que as pesquisas desenvolvidas na universidade, por meio da investigação científica, demonstram excessiva valorização da produção em grande proporção? Os temas recorrentes revelam o objetivo de, ao mesmo tempo obter o título de licenciado, promover no acadêmico - autor da pesquisa - a descoberta, a aquisição e o desenvolvimento de saberes, literários e práticos. Porém existem casos antagônicos em que o "produtivismo acadêmico", apresenta profunda relação com o sistema de avaliação da Capes. O mesmo compreende-se, pela ênfase exagerada na produção em grande quantidade de algo que possui pouca substância (FREITAS, 2011).

\section{CONSIDERAÇÕES SOBRE A DECORRÊNCIA PRODUTIVISTA NA UNIVERSIDADE}

As abordagens e a revisão da literatura, existentes sobre a educação superior, demonstram aspectos fundamentais para se pensar sobre o conhecimento constituído na universidade, e de forma harmônica, sobre a investigação científica e o desenvolvimento cultural. Estes, por sua vez, devem atentar para a descoberta, a aquisição e o incremento de saberes, sob o exercício constante da investigação e da atitude de problematização crítica do conhecimento. Isto significa, entretanto que, a fragmentação do ensino e da pesquisa abrange também a divisão intelectual (CHAUÍ, 2001).

Na eminência desta discussão, há a urgência de se estabelecer, nas instituições, a mediação entre educação e cultura, contra a exclusão social e em favor dos direitos, os quais sinalizam a possibilidade de politizar o espaço acadêmico, permitindo a aproximação das instituições com a sociedade, através da organização e da realização da discussão contínua sobre os seus limites e interesses.

Em síntese, propõe-se uma educação que proporcione as características necessárias para a democratização da sociedade, colaborando para a cidadania absoluta permanece de um projeto 
político voltado ao desenvolvimento de temas educacionais e culturais. Efetivamente, o capitalismo neoliberal é dotado de um sistema político institucional, neste caso a Universidade, com efeitos a mercantilização do conhecimento de acordo a empresas consumidoras de seu produto (SANTOS, 2013).

Tais inquietações apresentam-se, essencialmente, pesquisa à produção do conhecimento novo, relevante teórico e socialmente como uma urgência para se delimitar a relação necessária entre a sociedade e a instituição, que clama por atender as suas necessidades, o que significa repensar a atuação das instituições universitárias.

Nessa mesma linha interpretativa, Santos (2013) apresenta a expressão "produtivista" como uma desvantagem, predominando o quantitativo sobre o qualitativo, que interfere na produção científica e gera o que é denominado por produtivismo acadêmico. As mudanças quanto a essa categoria afetam os pesquisadores, desvirtuando o sentido pedagógico da universidade, de tal forma que acaba esvaziando as questões humanistas, tendo em vista à educação reduzida as ideologias de mercado dominante (CHAUÍ, 2001).

Considerando o viés produtivo da pesquisa, Leite e Lima (2012) ressaltam que esta tem sido direcionada as exigências de mercado. Ao se referir sobre à expansão da pesquisa científica na universidade, em termos de volume produzido, Chauí (2001) afirma, ser às demandas da sociedade. Nesse sentido, os discentes pesquisadores são instigados a produzirem conhecimento e, assim, passam a expressar as suas ações de acordo com a intenção mercantilista. Por vezes, esse conhecimento é a distinção entre o produzido que descentraliza a função institucional, produzindo conhecimento que vem ao encontro, necessitado pela sociedade como significativo (SANTOS, 2013).

Esse cenário põe em conflito a postura investigativa que permeia o trabalho pedagógico na universidade, uma vez que a sua intencionalidade é a construção do conhecimento. Acrescentandose ainda a relação com a aprendizagem dos discentes, já que a intencionalidade produtivista não valoriza a pesquisa como prática mediadora construtiva que a universidade se propõe a oferecer. Por conseguinte, redefinir a sua função é por em excelência o ensino e a pesquisa. Em decorrência do aligeiramento argumenta-se a qualidade das pesquisas realizadas que traduzem o trabalho acadêmico contemporâneo (CHAUÍ, 2001).

As noções de competências e excelências têm, muitas vezes, como critérios atender necessariamente a modernização econômica sobre o desenvolvimento social. A universidade, em função da abrangência que o modelo Capes avalia a produção por critérios específicos de produtividade, denota nova forma de fazer pesquisa e produzir ciência, conspirando contra a qualidade (NÓVOA, 2009; SOUZA; MARTÍNEZ, 2009). Tais fundamentos dizem respeito ao quanto se produz, em quanto tempo se produz e quais os critérios de produtividade, o que opera tipicamente na inversão ideológica sobre a qualidade e a quantidade.

Observando a docência na medida dessa produtividade, extinguindo a qualidade universitária, justificando-se pelas "combinações flexíveis", consequentemente, a propósito, a reforma separa a universidade e o centro de pesquisa já que não há definição de critérios para "medir" a qualidade da docência. Para tanto, o aspecto de realização é hoje mais do que o resultado de procedimentos metodológicos, são aspectos subjetivos do pesquisador (FAZENDA, 1991).

A universidade é um dos lugares em que se constitui a produção de conhecimento, tornando-o significativo e indispensável ao paradigma de desenvolvimento que a sociedade adquiriu para si. Porém, o paradigma contemporâneo é responsável pela produtividade. Ao se constituir pela perspectiva produtivista, cujo valor maior é a acumulação da quantidade em que se destaca como mecanismo a superar a situação insatisfatória dos conhecimentos adquiridos durante a vida acadêmica (CHAUÍ, 2001).

\section{A PESQUISA ACADÊMICA DOS LICENCIANDOS NAS HUMANIDADES}

A instituição selecionada na pesquisa expõe suas características identitárias como Faculdades Integradas e é de caráter comunitário. A maioria de seus acadêmicos é oriunda de municípios vizinhos e tem como perfil alunos que estudam à noite e trabalham durante o dia, para custear seus estudos.

Para fins de caracterização, cabe dizer que o curso de Pedagogia, das Faculdades Integradas de Taquara - FACCAT, com Habilitação em Anos Iniciais do Ensino Fundamental foi autorizado pelo MEC em 27 de setembro de 2000 teve seu reconhecimento em abril de 2007 . Sendo uma instituição 
privada, tem seu regimento de acordo com a mantenedora, a Fundação Educacional Encosta Inferior do Nordeste - FEEIN - que tem em sua normativa preocupação com o ensino voltado ao incentivo da pesquisa e da extensão durante o processo de formação profissional de pedagogos, atendendo às particularidades da identidade regional.

A FACCAT iniciou suas atividades partindo da necessidade levantada pelos municípios de Taquara, Rolante, Igrejinha, Três Coroas e São Francisco de Paula. A intenção era ofertar o ensino superior no município de Taquara/RS, por meio da amplificação do Curso de Economia da Universidade do Vale do Rio dos Sinos - UNISINOS - situada na região Metropolitana de Porto Alegre/RS. Ao obter sua autonomia acadêmica - pelos cursos de Ciências Contábeis e Administração - a FACCAT seguidamente conquistou a autorização para instituir o curso de Pedagogia que se assemelha as particularidades da comunidade, passando a exercer projetos que visam à qualificação do ensino na região e a contribuir com recursos humanos, buscado pelo zelo ao desenvolvimento cultural e sócio-político.

Levando em consideração as novas Diretrizes Curriculares apresentadas ao Curso de Pedagogia, aprovada pelo Conselho Nacional de Educação em 13 de dezembro de 2005. Após, homologada pelo Ministério da Educação em 15 de maio de 2006, passa a adequar-se as normas aos fundamentos que direcionam o aluno do curso de Pedagogia a exerce com disposições os conhecimentos relacionados entre à teoria e a prática. Com efeitos interdisciplinares, buscando no contexto a ênfase social. Esse discurso se constitui pela multiplicidade das ciências, das culturas, das artes e da cotidianidade que busca a interpretação das relações constituídas dentro do processo educativo (BRASIL, 2006).

O curso de Licenciatura em Pedagogia das Faculdades Integradas de Taquara propõe, em sua filosofia, a promoção de atitudes voltadas ao exercício do viver e do conviver de forma ética, equânime e sensível, assim como prima pelo exercícicio das funções de magistério, de pesquisa e de gestão no Ensino Básico, em contextos, escolares e não escolares. Isto é, formar Licenciados em Pedagogia para atuar em espaços escolares e não escolares, do Ensino Básico, possibilitando exercer as funções inerentes ao magistério, à pesquisa e à gestão capaz de diagnosticar e apresentar soluções, tendo como ferramenta a pesquisa, a reflexão, e o compromisso com uma sociedade responsável, fraterna e democrática.

O curso de Pedagogia direciona a edificação da teoria metodológica coincidentemente com o processo de formação, essa direcionada às atitudes de investigação e pesquisa presente à indecisão da implantação social de sua área de formação. Por isso, o curso apresenta como conceito a percepção e a reflexão da indagação, na perspectiva de formar um sujeito integralo. $O$ mesmo, articula estratégias profissionais e uma sistemática flexível com integração entre o todo, promovendo a extensão da toria à prática - tomando como segmento o nível mais complexo dos conhecimentos - adquirindo uma percepção, crítica, rigorosa e científica da realidade.

O curso está embasado pelas Diretrizes Curriculares Nacionais, as quais especificam que a sua função é formar o pedagogo licenciado para atuar na Educação Infantil, nos anos iniciais do Ensino Fundamental, nos cursos de Ensino Médio, na modalidade Normal e em cursos de Educação Profissional na área de serviços e apoio escolar, bem como, aquelas que preveem conhecimentos pedagógicos. Por essas razões, objetiva a atuação do sujeito capaz de integrar-se a realidade educacional. A fim de proporcionar novos conhecimentos, explorando a realidade sociocultural, entre as diferentes propostas curriculares, para desenvolverem suas experiências sobre o processo de ensinar e aprender.

Já o curso de licenciatura em História, encontra-se de acordo com a Resolução CNE/CP $n^{\circ}$ 1, de 18 de fevereiro de 2002. Em decorrência, autorizou a redução da carga horária dos cursos e com a Resolução CNE/CES n 13, de 13 de março de 2002, instituindo as Diretrizes Curriculares Nacionais para o curso de História em nível de formação superior. Como propósito, a atuação na Educação Básica, a instituição passa a formar professores em nível superior no curso de licenciatura plena em História pelas Faculdades de Educação de Taquara - FAETA.

No ano de 2000, a Faculdade de Educação de Taquara (FAETA) encaminhou ao MEC a solicitação de autorização para implantação do Curso de História, obtendo aprovação em 2001. No ano de 2002, o MEC instituiu as novas diretrizes para a formação de professores da educação básica, em nível superior, com isso instituiu-se o curso de licenciatura plena. De acordo com a Resolução CNE/CP n 1/2002 e o Parecer CNE/CP n² 28/2002, a nova proposta entrou em vigor a 
partir do primeiro semestre de 2006, passando assim as instituições de ensino superior atender a legislação vigente.

As alterações realizadas na estrutura curricular apresentaram como objetivo a formação de um professor pesquisador e a ampliação do conhecimento sobre a história regional. As resoluções estabelecidas pelo Ministério da Educação regulamentaram as mudanças na estrutura curricular, consequentemente, discutidas em reuniões de professores. Portanto, as atividades práticas que se realizam no Curso de História foram planejadas dentro do projeto pedagógico e acontecem desde 0 início do processo formativo e se estendem ao longo de todo esse processo.

O objetivo principal do Curso de História é a formação de professores, sendo as competências desenvolvidas baseiadas na legislação vigente, nas Diretrizes Curriculares Nacionais, no Parecer CNE/CP n 9/2002, no Parecer CNE/CES n 492/2001 e nas necessidades sociais detectadas na atuação da instituição junto à sua comunidade regional.

De acordo com o projeto de criação do curso, a função da História [e do professor de História] é fornecer explicações para as sociedades humanas, sobre suas origens e as transformações pelas quais estas passaram. Ou seja, os eventos históricos devem ser vistos como fruto de ação humana e não de entidades abstratas, independentes do homem e determinantes absolutas sobre ele.

Nesse sentido, para entendermos a relação indivíduo - sociedade, conforme já expresso, é preciso considerar que a História situa a humanidade no tempo, dando referências às ações dos indivíduos num determinado espaço, ou seja, o processo de desenvolvimento histórico apresenta diferentes relações espaço-temporais.

Em termos espaciais, a história pode ser estudada segundo os níveis de análise micro e macro. O estudo de aspectos históricos que se situam no ambiente Local/Regional proporciona o conhecimento sobre as peculiaridades intrínsecas que, em nível macro, certamente passariam despercebidos. Tais detalhes, portanto, nos permitem a compreensão sobre as propriedades e seus significados sociais, culturais, políticas ou econômicas de uma ou mais comunidade e as formas de inserção que abrange determinado contexto histórico. Para este estudo - em específico no campo da História - é importante que o diálogo interdisciplinar, isto é, através da pesquisa prime por trocas com outras áreas do conhecimento realizando as ideias que se relacionam entre si.

Partindo-se de uma pesquisa essencialmente qualitativa, procurou-se identificar os temas presentes generalizando os argumentos sobre a convicção produtivista. Buscou-se realizar uma leitura crítica sobre essas produções dos trabalhos de conclusão, articulando-os com a problemática apresentada sobre a valorização excessiva e a produção em grande quantidade. Essa produção, esta focada para dar conta dos índices exigidos, pela produtividade provocando distorções que parecem contemplar e contrariar a tradição histórica da universidade (CHAUÍ, 2001).

O recorte temporal da pesquisa compreende o período de 2007 à 2016. Durante o intervalo de 10 anos, procurou-se levantar o significado e dos temas abordados pelos concluintes dos dois cursos de graduação da IES, identificando nesse processo de construção de suas pesquisas de Trabalho de Conclusão de Curso (TCC), quais os temas que mereceram maior atenção por parte dos acadêmicos.

Tendo em vista que o curso de Licenciatura em História da FACCAT foi criado em 2002 e sua primeira turma de formandos foi somente em 2008, ressaltamos que no caso dos Trabalhos de Conclusão de Curso da licenciatura em História, o período de abrangência da pesquisa foi entre 2008 e 2016, ou seja, de 09 anos.

De início apresenta-se, a diversidade dos temas pesquisados pelos acadêmicos do Curso de Pedagogia. Nos gráficos abaixo representa-se, a percepção sobre a multiplicidade de temas, associados ao contexto da formação de professores voltados para a atuação na Educação infantil e nos Anos Iniciais do Ensino Fundamental. 
Gráfico 1 - Produção acadêmica do curso de Pedagogia

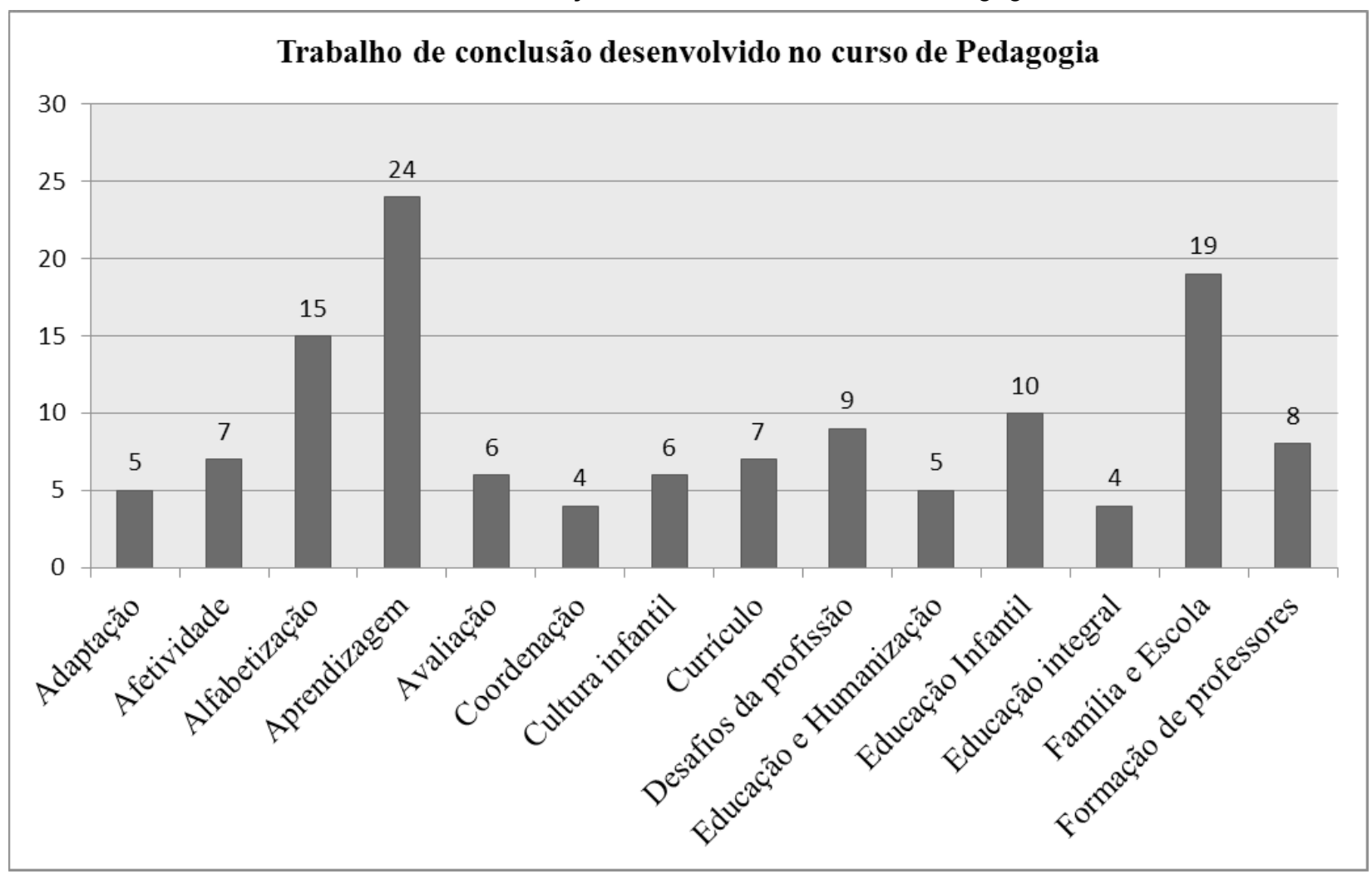

Fonte: Elaborado pelos autores.

Gráfico 2 - Produção acadêmica do curso de Pedagogia

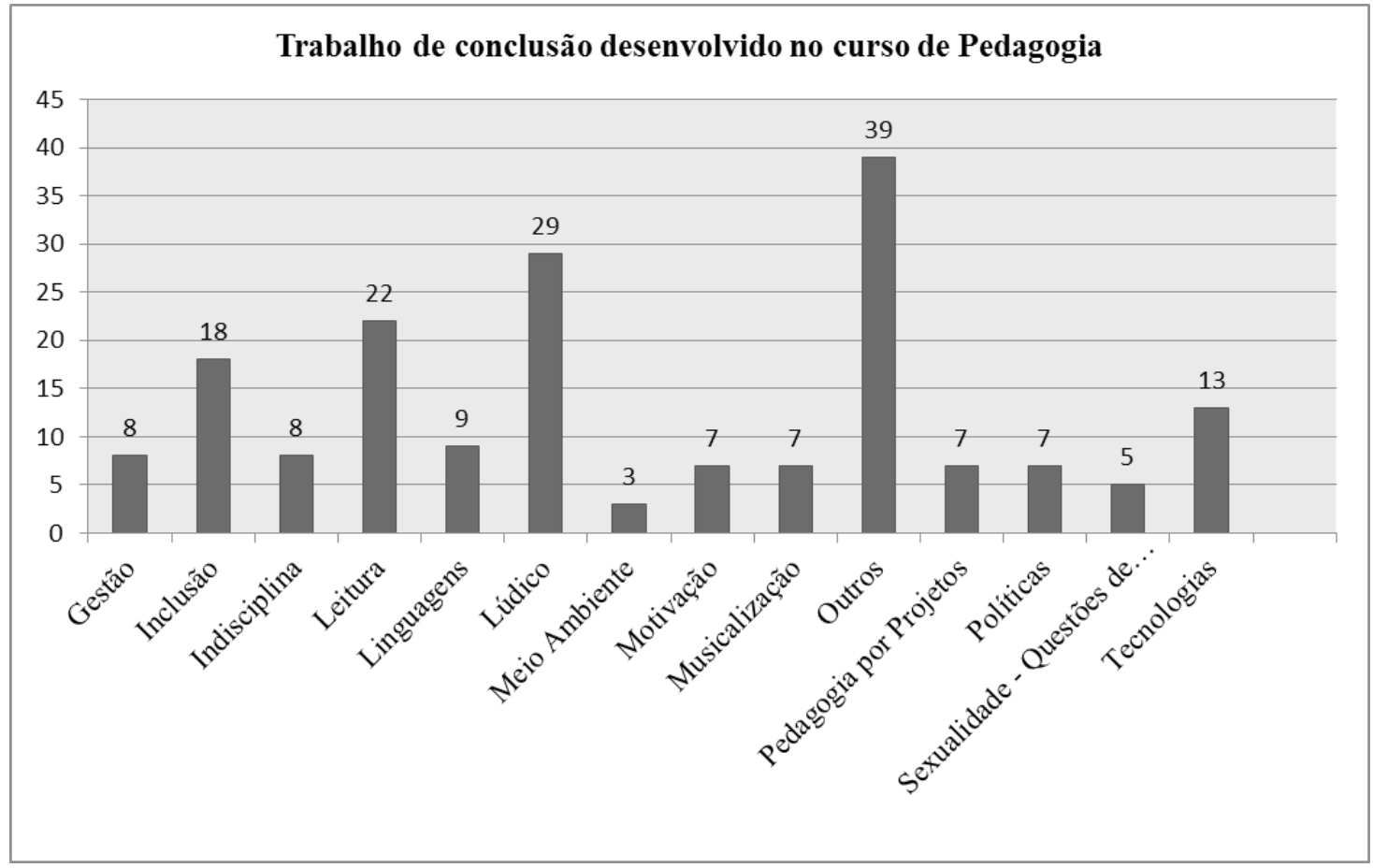

Fonte: Elaborado pelos autores.

Porém, ainda que tenhamos uma significativa variedade de temas de pesquisa, ao observar o gráfico de forma mais cuidadosa, percebemos que os assuntos abordados [que durante uma década totalizarm 311 trabalhos] de forma mais recorrente e que mereceram maior atenção dos academicos foram: o lúdico, abordado 29 (vinte e nove) vezes, questões voltadas a aprendizagem somando 24 
trabalhos, as questões de leitura por 22 acadêmicos, a relação entre a família e a escola em 19 trabalhos e ainda, os aspectos de inclusão, que totalizaram 18 trabalhos.

As questões lúdicas, no Curso de Pedagogia, são consideradas como as ações desenvolvidadas pelas crianças como brincadeiras por espontaniedade, a criança enquanto brinca aprende (FREINET, 1985). Nesse contexto, a criança é interpretada como protagonista ativa do seu próprio conhecimento. Tendo em vista sua integridade comunicativa exploratória, físico, mental, emocional e social (MALUF, 2003).

Sobre as questões de aprendizagem, os estudos foram delineados por questões de dificuldades durante o processo, como métodos e estratégias tem auxiliado professores a desenvolver questões práticas em sala de aula. Considerando que cada indivíduo tem seu tempo e sua forma para desenvolver todos esses aspectos. É importante o educador aceitar que cada sujeito desenvolva sua construção social, cultural e uma história de vida, o aprendizado ocorre sendo motivador de interesse, habilidade em compartilhar experiências e a habilidade de interagir com os diferentes contextos (SANTOS, 2008).

Tendo em vista o incentivo à leitura, consideramos que os aspectos associados à epistemologia do processo despertaram a atenção de muitos acadêmicos. É nessa perspectiva que Nunes et al. (2012) salienta ser preciso entender que o incentivo a leitura não é um dom, mas um hábito que se adquire e se desenvolve. A presente discussão refere-se à leitura na perspectiva de hábito de ler, considerando ainda o prazer proporcionado pela leitura enquanto possibilidade de ampliar conhecimento e estimular a imaginação. Vale destacar a participação dos pais, pois no processo de formação do leitor é de suma importância a relação com a família para que a motivação aconteça (FREIRE, 2000).

As questões sobre a relação de família e escola também requer atenção especial, uma vez que na contemporaneidade as relações entre escola e família, assim como outras instituições, vêm passando por profundas transformações. A família, nesse contexto se desconstituiu do pensamento burguês, caracterizada com pai, mãe e filhos, respeitando os pensamentos e mandos centrados na figura paterna. Nesta acepção, a escola se constitui in locus reprodutivo das desigualdades sociais e culturais, isto é, a escola conjectura determinadas competências que devem ser adquiridas na instituição familiar. Portanto, a consistência que a escola possui sobre a construção dessa parceria é fundamental, levando em consideração a necessidade enfrentada pela família, a vivenciar situações que Ihes possibilitem se sentirem participantes ativos nessa parceria.

Szymanski (2003) ressalta que o conhecimento da criança tem início no concreto, naquilo que participa, que vivencia, e que aos poucos vai se incorporando, na família conhecimentos abstratos. A partir desse princípio, a escola enquanto espaço de ensino e aprendizagem dos conteúdos, sistematiza as relações interpessoais de cada educando procurando dar o atendimento necessário para seu desenvolvimento.

Além dos aspectos relacionados à família e a escola, considera-se atentamente, os aspectos de inclusão e as considerações acerca de acolher todas as pessoas, sem exceção, ao sistema de ensino, independentemente das condições psicológicas, de classe, cor e físicas é de maneira comum à inclusão educacional.

Neste caso, há de se considerar as adaptações curriculares para assim desenvolver estratégias de aprendizagem que promovam o conjunto de elementos e a eficácia educativa, a fim de contribuir, com o sistema de inclusão e com o atual estado dos educacionais. Afirma Rosa (2005) que as adaptações curriculares se caracterizam pela procura de uma maior flexibilidade e dinamismo do ensino e da formação de cada educador.

Num segundo momento, apresentamos o gráfico com os resultados do levantamento realizado com os Trabalhos de Conclusão do Curso de História, que assim como no caso da Pedagogia, apresentam uma diversidade de temas de pesquisa. Entretanto, algumas temáticas mereceram maior atenção por parte dos acadêmicos, demonstrando certa tendência a trabalhar com temas associados às questões mais contemporâneas e que, em nosso entendimento, se articulam com o fazer pedagógico do professor de história no contexto atual da escola brasileira. 
Gráfico 3 - Produção acadêmica do curso de História

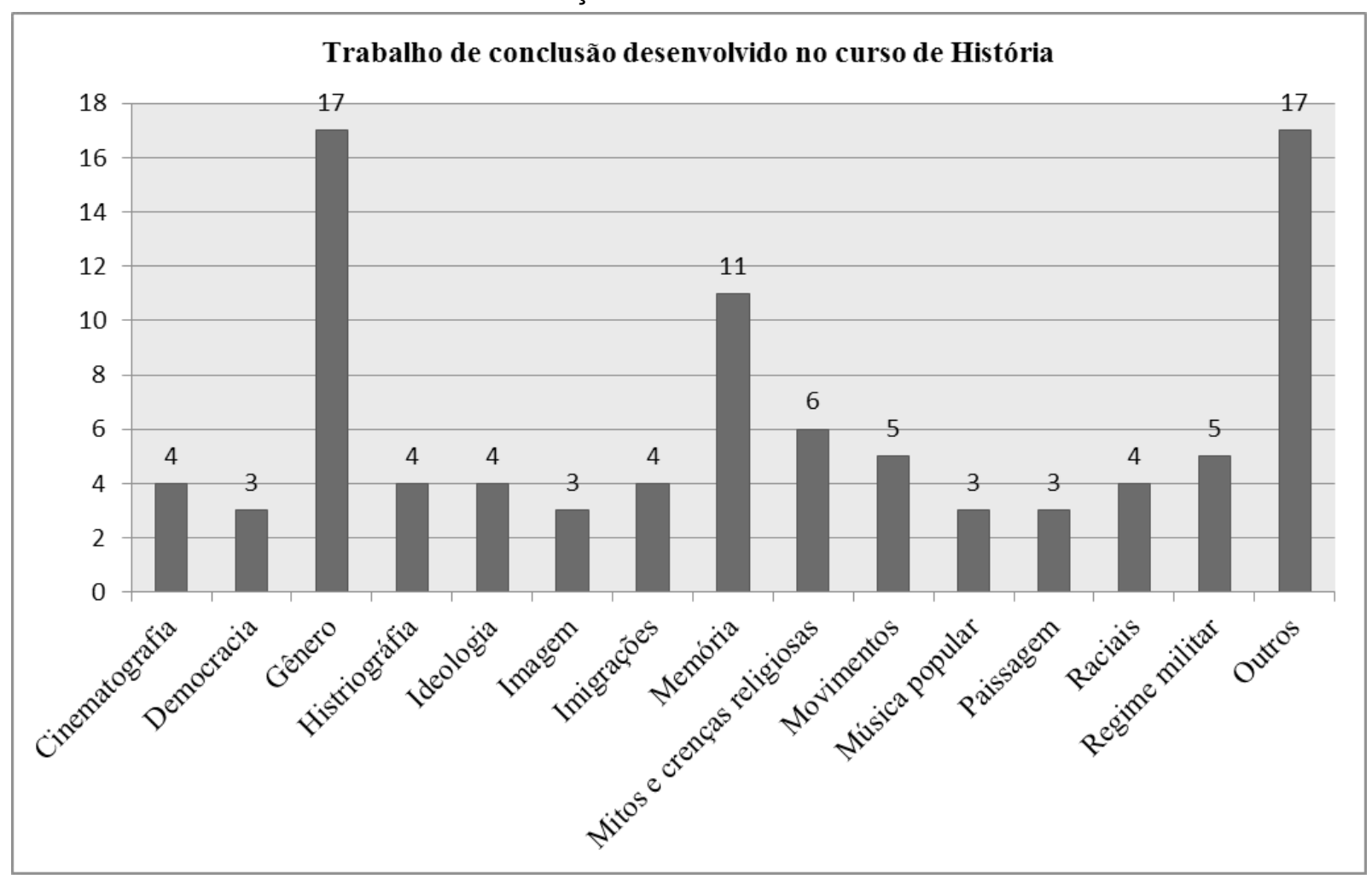

Fonte: Elaborado pelos autores.

O levantamento identificou um total de 93 Trabalhos de Conclusão de Curso, publicado entre 2007 e 2016. As pesquisas apresentadas deram ênfase a temas como: gênero com 17 trabalhos, memória, com 11 pesquisas realizadas, mitos e crenças religiosas com 06 trabalhos. Os demais trabalhos apresentam uma significativa diversidade de temas e recortes, que abrangem diversos campos da história, numa perspectiva interdisciplinar.

Sobre os estudos realizados sobre as questões de gênero, considera-se que apesar dos avanços consideráveis das últimas décadas, ainda é um tema em construção. Por certo, os resultados têm se mostrado mais "híbridos", ou melhor, ao processo de formação e junção de princípios em distintas línguas, cujas relações apresentam uma tendência notável, isto é, à interação entre culturas de uma forma recíproca, favorecendo o seu convívio e integração assente numa relação baseada no respeito pela diversidade e no enriquecimento mútuo (CANCLINI, 2015).

Fenômenos estudados que estão intrinsecamente postos em contato com os dias de hoje, com questões que envolvem globalização, migração e influências hegemônicas como realidades efetivas, o que resulta em estudos interculturais entre as civilizações, a proporcionar modelos e sistemas de sociabilidade de uma para com a outra.

Outro tema de destaque no Curso de História é a problemática da memória. Nesse sentido, cabe lembrar que para Le Goff (2003), a memória é uma constituinte necessária no que se habitua a chamar de autenticidade, seja ela individual ou coletiva. Nesse sentido, a memória não é apenas a ação conquistada, todavia também uma ferramenta de domínio. Permanece uma pendência pelo predomínio da rememoração e do símbolo, estabelecendo sobre aquilo que deve permanecer na lembrança e aquilo que deve ser esquecido.

O espaço que ocupa a memória faz parte da essência e, dessa forma, tornam-se concretos, despertando os sentimentos e os interesses predominantes de cada época, os quais determinam a permanência na memória ou o esquecimento dos episódios e de seus personagens.

Outra temática recorrente nos trabalhos é a religiosidade. As questões de religiosidade [e a diversidade inscrita em seu contexto] se definem nas pesquisas a partir das tramas sociais e das relações interculturais, as quais objetivam pluralizar valores e princípios arraigados no tempo que acabam por influenciar em seguimentos diversificados. Assim, a expansão e a diversidade entre as religiões que enseja o desenvolvimento de forças culturais, impactam nas questões das mais variadas naturezas. Cujo objetivo é fazer parte do elo de aproximação entre criatura e criador (BOFF, 2000). 
A partir do levantamento de um total de 404 produções, resultantes dos Trabalhos de Conclusão de Curso das licenciaturas em Pedagogia e História da FACCAT, percebe-se uma clara relação entre os temas selecionados e a preocupação dos acadêmicos [autores] com a discussão de temas voltados ao fazer pedagógico de sua profissão. Tanto no caso da formação de professores para atuação na Educação infantil e Anos Iniciais da Educação Básica [Pedagogia] como no caso da formação de professores de História para os Anos Finais e Ensino Médio, a aproximação dos temas de pesquisa com o contexto escolar são perceptíveis.

Essa constatação corrobora com a hipótese formulada inicialmente, de que a formação de professores no campo das Humanidades apresenta uma expressiva aproximação com o campo de atuação. A necessidade de aproximação das pesquisas acadêmicas, que resultam nas publicações cientifica, contribui cada vez mais para a formação de professores com visão crítica e capaz de intervir positivamente nos espaços de atuação profissional, para os quais a Universidade prepara. $\mathrm{O}$ ato de pesquisar é satisfatório, mas não se pode atribuir ao produtivismo acadêmico, toda a responsabilidade pelos acontecimentos calamitosos da pesquisa (KUHLMANN JR, 2015).

Através da análise, percebe-se, uma forte aproximação entre os saberes produzidos no meio acadêmico e as necessidades presentes nos espaço de atuação dos concluintes dos Cursos de Pedagogia e História da FACCAT. Problematizando questões contemporâneas bastantes próximas da realidade regional, os licenciandos demonstram preocupação no tratamento com temas inerentes à sua prática cotidiana.

E preciso lembrar que no cenário investigado, parte significativa dos formandos já atua como professor nas redes pública ou privada de educação. Além disso, é preciso considerar que a maioria daqueles que ainda não tem inserção nas escolas, pretende desempenhar o ofício de professor a partir do memento da conclusão da licenciatura.

Investigar temas relacionados com o ofício da docência manifesta, de acordo com nosso estudo, demonstra preocupação antecipada dos licenciandos, os quais em sua trajetória acadêmica, se veem desafiados a pensar sobre as estratégias de ação no espaço de atuação docente, de forma mais particular, sobre as situações-problemas que se apresentam no cotidiano da escola contemporânea.

A diversidade [compreendida na sua perspectiva interdisciplinar e no contexto das discussões recentes das humanidades] parece ser o eixo predominante nas pesquisas realizadas pelos formandos dos Cursos de Pedagogia e História, uma vez que temas como a inclusão/exclusão, as relações família/escola, o brincar e a leitura se colocam como os principais desafios a serem percorridos pelos acadêmicos da Pedagogia. Processo semelhante aparece no levantamento realizado com os acadêmicos de História, no qual as questões de gênero, religião/religiosidade e os processos que envolvem a manipulação da memória, aparecem, em maior número nas pesquisas.

Um elemento que corrobora com essas afirmações é o fato de que ambos os Cursos oferecem aos acadêmicos a oportunidade de participação no Programa Institucional de Bolsa de Iniciação à Docência (PIBID), que através de convênio firmado entre a FACCAT e a CAPES, permitem aos licenciandos, maior inserção no meio educacional da região de atuação da IES. A atuação dos acadêmicos, nas atividades desenvolvidas pelo PIBID nas escolas públicas da região do Vale do Paranhana aproxima o meio acadêmico da sociedade, através da atuação dos bolsistas na sala de aula da Educação Básica, contribuindo de forma significativa para a compreensão do contexto social e sobre os desafios que se colocam.

\section{CONSIDERAÇÕES FINAIS}

O estudo permitiu o aprofundamento da discussão sobre os temas de pesquisa selecionados para o desenvolvimento dos Trabalhos de Conclusão de Curso (TCC) das licenciaturas em Pedagogia e História, compreendidas no campo das Humanidades. A pesquisa revelou princípios e aspectos históricos que envolvem os cursos de formação docente e a necessidade de um amplo processo dialógico entre as áreas de conhecimento, principalmente no tocante às áreas de História e Pedagogia.

Em cada contexto estudado as sínteses exploradas demonstram aparência específica, que se articula com os diversos mecanismos históricos e político-culturais especificas dos cursos e da sua realidade prática. A afirmação das alteridades étnicas, de gênero, orientação sexual, religiosas, entre outras, manifesta-se de modos plurais, assumindo a diversidade de expressões e linguagens. As 
problemáticas estudadas apresentam-se em vasta multiplicidade, autenticadas pelo reconhecimento político e cultural.

Tendo em vista esses aspectos, levamos em consideração, questões como as influências exercidas pelos professores nos respectivos cursos e suas relações estabelecidas durante o processo, com os acadêmicos [autores das pesquisas]. Observou-se a necessidade de fazer referência aos resultados da pesquisa, tendo como base a elaboração de ações que se desenvolvem no campo da promoção e da pluralidade cultural.

Vale ressaltar [ainda em tempo] que a formação dos profissionais do magistério empenhase no compromisso social e ético. Ao tecer a critica sobre o produtivismo acadêmico que tem por excelência desqualificar a prática docente e a qualidade cientifica, mas que apresente a notoriedade, rompendo com o individualismo das experiências pedagógicas. Buscou-se articular a teoria e a prática no processo de formação docente, esta fundada no domínio de conhecimentos científicos, primordial da profissionalização docente, possui obrigações de integrar-se ao cotidiano da escola e considerar os diferentes saberes e a experiência docente.

Entre os resultados obtidos, é importante assinalar a imposição para a obtenção de altos índices de produtividade no contexto universitário [e que servem de parâmetros para as avaliações externas]. Consideramos fundamental, na contramão da ideia de "produção em quantidade", a aproximação do saber acadêmico com os saberes que se constituem pela prática docente exercida na sociedade e de forma mais particular, no contexto local ou regional.

Tendo em vista a característica de uma sociedade impregnada pelo modelo neoliberal, no qual as relações sociais de produção se sustentam pela formação e qualificação profissional, cabe questionar em que medida o conhecimento produzido pela academia tem contribuído para o desenvolvimento da sociedade - de forma integral.

$\mathrm{Na}$ realidade, a melhor demonstração para relatar a corporação capitalista atual seria a consistência da "sociedade da inteligência", porquanto inteligência transmite às experiências, enquanto o conhecimento aos saberes já formalizado.

Em síntese, a mudança inovadora na educação será possível por meio de uma reestruturação da formação docente, capacitada para trabalhar com os diversos saberes culturalmente constituídos. Destacando o papel da Universidade, na promoção do diálogo entre saberes, entre disciplinas e áreas de conhecimento, numa perspectiva do hibridismo cultural, é imprescindível compreender a sociedade contemporânea como algo cada vez mais plural, multifacetado e complexo. 


\section{REFERÊNCIAS}

BIANCHETTI, L.; VALLE, I. R.; PEREIRA, G. R. de M. O fim dos intelectuais acadêmicos?: induções da Capes e desafios às associações científicas. Campinas, SP: Autores Associados, 2015.

BOFF, L. Tempo de transcendência: o ser humano como um projeto infinito. 3. ed. Rio de Janeiro: Sextante, 2000.

BRASIL. Parecer CNE/CP n ${ }^{\circ} 28$, aprovado em 2 de outubro de 2001. Dá nova redação ao Parecer CNE/CP 21/2001, que estabelece a duração e a carga horária dos cursos de Formação de Professores da Educação Básica, em nível superior, curso de licenciatura, de graduação plena. Homologado em 17 jan. 2002. Diário Oficial da União. Brasília, DF, 18 jan. 2002a. Seção 1, p. 31. Disponível em: <http://portal.mec.gov.br/cne/arquivos/pdf/028. pdf>. Acesso em: 23 jan. 2017.

Parecer CNE/CES no 492, aprovado em 3 de abril de 2001. Diretrizes Curriculares Nacionais dos cursos de Filosofia, História, Geografia, Serviço Social, Comunicação Social, Ciências Sociais, Letras, Biblioteconomia, Arquivologia e Museologia. Homologado em 4 jul. 2001. Diário Oficial da União. Brasília, DF, 9 jul. 2001. Seção 1e, p. 50. Disponível em: <http://portal.mec.gov.br/cne/arquivos/pdf/ CES0492.pdf>. Acesso em: 23 jan. 2017.

Parecer CNE/CP n ${ }^{\circ}$ 9, aprovado em 8 de maio de 2001. Diretrizes Curriculares Nacionais para a Formação de Professores da Educação Básica, em nível superior, curso de licenciatura, de graduação plena. Homologado em 17 jan. 2002. Diário Oficial da União. Brasília, DF, 18 jan. 2002b. Seção 1, p. 31. Disponível em: <http://portal.mec. gov.br/cne/arquivos/pdf/009.pdf>. Acesso em: 23 jan. 2017.

Parecer CNE/CP $n^{\circ} 5$, aprovado em 13 de dezembro de 2005. Diretrizes Curriculares Nacionais para o Curso de Pedagogia. Homologado em 20 dez. 2005. Diário Oficial da União. Brasília, DF, 15 maio 2006. Disponível em: <http://portal.mec. gov.br/cne/arquivos/pdf/pcp05_05.pdf>. Acesso em: 27 mar. 2017.

Resolução CNE/CES no 13, de 13 de março de 2002. Estabelece as Diretrizes Curriculares para os cursos de História. Diário Oficial da União. Brasília, DF, 9 abr. 2002c. Seção 1, p. 33. Disponível em: <http://portal.mec.gov.br/cne/arquivos/pdf/ CES132002.pdf>. Acesso em: 23 jan. 2017.

Resolução CNE/CP n ${ }^{0} 1$, de 18 de fevereiro de 2002. Institui Diretrizes Curriculares Nacionais para a Formação de Professores da Educação Básica, em nível superior, curso de licenciatura, de gra- duação plena. Diário Oficial da União. Brasília, DF, 9 abr. 2002d. Seção 1, p. 31. Disponível em: <http:// portal.mec.gov.br/cne/arquivos/pdf/rcp01_02.

pdf>. Acesso em: 23 jan. 2017.

CANCLINI, N. G. Culturas híbridas. São Paulo: Edusp, 2015.

CHAUÍ, M. Escritos sobre a Universidade. São Paulo: UNESP, 2001.

FAZENDA, I. Metodologia da pesquisa educacional. 3. ed. São Paulo: Cortez, 1991.

FREINET, C. Pedagogia do bom senso. São Paulo: Martins Fontes, 1985.

FREIRE, P. A importância do ato de ler em três artigos que se completam. São Paulo: Cortez Ed., 2000.

FREITAS, M. E. de. O pesquisador hoje: entre o artesanato intelectual e a produção em série. Cadernos EBAPE.BR, v. 9, n. 4, p. 1158-1163, 2011.

KUHLMANN JR, M. Produtivismo acadêmico, publicação em periódicos e qualidade das pesquisas. Caderno de Pesquisa, v. 45, n. 158, p. 838-855, 2015.

LE GOFF, J. História e memória. 5. ed. Campinas: UNICAMP, 2003.

LEITE, D.; LIMA, E. G. dos S. Conhecimento, avaliação e redes de colaboração: produção e produtividade na Universidade. Porto Alegre: Sulina, 2012.

MACEDO, E.; SOUZA, C. P. de. A pesquisa em educação no Brasil. Revista Brasileira de Educação, v. 15, n. 43, p. 166-176, 2010.

MALUF, Â. C. M. Brincar: prazer e aprendizado. Petrópolis, Rj: Vozes, 2003.

NÓVOA, A. Formação contínua de professores: realidades e perspectivas. Aveiro: Universidade de Aveiro, 1991

Modelos de análise em educação comparada: o campo e a carta. In: SOUZA, D. B.

de.; MARTÍNEZ, S. A. (Org.). Educação comparada: rotas de além-mar. São Paulo: Xamã,

2009.

NUNES, I. et al. A importância do incentivo à leitura na visão dos professores da escola Walt Disney. Revista Eletrônica da Faculdade de Alta Floresta-REFAF, v. 1, n. 2, 2012. Disponível em: <http:// 
faflor.com.br/revistas/refaf/index.php/refaf/article/ view/53/pdf>. Acesso em: 18 mar. 2017.

ROSA, S. P. da S. Fundamentos teóricos e metodológicos da inclusão. Curitiba: IESD, 2005.

SANTOS, B. de S. A Universidade no século XXI: para uma reforma democrática e emancipatória da Universidade. 3. ed. São Paulo: Cortez, 2013.
SANTOS, J. C. F. dos. Aprendizagem significativa: modalidades de aprendizagem e o papel do professor. Porto Alegre: Mediação, 2008.

SOUZA, D. B. de.; MARTíNEZ, S. A. (Org.). Educação comparada: rotas de além-mar. São Paulo: Xamã, 2009.

SZYMANSKI, H. A relação família - escola: desafios e perspectiva. Brasília: Plano Editora, 2003. 